\author{
Military Technical College \\ Kobry Elkobbah, Cairo, \\ Egypt.
}

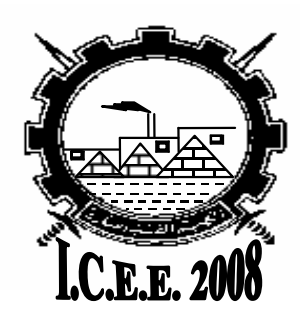

$4^{\text {th }}$ International Conference On

Chemical \& Environmental

Engineering

27-29 May 2008

\title{
IMPROVEMENT OF THE PROPERTIES OF INSULATING POLYMERS USING ARAMID FIBER FOR SOLID ROCKET MOTOR INSULATION
}

\author{
Ashraf Fathy Ahmed ${ }^{*}$, and Suong V. Hoa*
}

\begin{abstract}
Development and characterization of asbestos-free rubbers for use as rocket motor insulators are presented. Such insulation is based on aramid fiber in the pulp form as reinforcement for Ethylene Propylene Diene Monomer (EPDM) in the liquid form.

Aramid fiber (Kevlar) in the pulp form has been used and characterized as EPDM filler material. This method permits manufacturing EPDM rocket motor insulation in which Kevlar pulps are dispersed and immobilized in the EPDM polymeric matrix. A detailed description and procedure for the mixing cycle is explained. The curing methodology was justified. Kevlar pulp/EPDM has been shown to exhibits better thermal properties than its asbestos containing counterpart. Its thermal characteristics however fall short of some of the best asbestos insulators.
\end{abstract}

Insulation material description, processing and manufacturing techniques are discussed along with thermal properties (effective thermal conductivity, effective specific heat capacity and effective thermal diffusivity). The physical and mechanical properties (density, hardness, tensile strength and elongation) of different compositions were obtained. The ablation resistance was measured. Thermogravimetric analyses versus Kevlar pulp content, as well as a differential scanning calorimetry are discussed. The effect of changing Kevlar pulp volume fraction was studied. Also a comparison of Kevlar pulp/EPDM's performance (both thermally and mechanically) with other rocket motor insulating materials was done.

Kevlar pulp filled EPDM has been shown to exhibit better thermal, mechanical, physical and ablative properties than its asbestos containing counterpart.

\section{KEYWORDS}

Composites for aerospace.

Graduate student, Concordia Center for Composites, Department of Mechanical and industrial Engineering, Center for Research on Polymers and Composites (CREPEC), Concordia University, Montreal, Quebec, Canada

** Professor, Director, Concordia Center for Composites, Department of Mechanical and industrial Engineering, Center for Research on Polymers and Composites (CREPEC) Concordia University, Montreal, Quebec, Canada 


\section{NOMENCLATURE}

AP

$\mathrm{C}_{\mathrm{p}}$

DSC

EPDM

$\mathrm{K}$

$\mathrm{KP}$

PCA

$\mathrm{Phr}$

TGA
Ammonium Polyphosphate

Specific Heat, J/kg. ${ }^{\circ} \mathrm{K}$

Differential Scanning Calorimetery

Ethylene Propylene Diene Monomer

Thermal Conductivity, $\mathrm{W} / \mathrm{m}$. ${ }^{\circ} \mathrm{K}$

Kevlar Pulp

Peroxide Cross linking Agent

Part per hundred ratio

Thermo Gravimetric Analysis

\section{INTRODUCTION}

Solid rocket motors typically include an outer case or shell that houses solid propellant grains. The rocket motor case is conventionally manufactured from a rigid, yet durable, material such as steel or filament-wound composite. The propellant is housed within the case and is formulated from a composition designed to undergo combustion and thereby produces the requisite thrust for attaining rocket motor propulsion. Internal insulation in a solid rocket motor is a layer of heat-barrier material placed between the internal surface of the case and the propellant. [1-3] The primary function of internal insulation is to prevent the rocket motor case from reaching temperatures that may endanger its structural integrity. Typically, the insulation is bonded to the inner surface of the case and is generally fabricated from a composition capable of withstanding the high temperature gases produced when the propellant grains burn. The combustion of solid rocket propellant generates extreme conditions within the case of the rocket motor. For example, temperatures inside the rocket motor case typically reach $2,760^{\circ} \mathrm{C}\left(5,000^{\circ} \mathrm{F}\right.$.), and interior pressures may exceed 1500 psi (10.35 MPa). These factors combine to create a high degree of turbulence within the rocket motor case. In addition, particles are typically entrained in the gases produced during propellant combustion. Under the turbulent environment, these entrained particles can erode the rocket motor insulation. If the insulating layer and liner are pierced during rocket motor operation, the casing is susceptible to melting or degradation, which can result in failure of the rocket motor. Thus, it is crucial that insulation compositions withstand the extreme conditions experienced during propellant combustion and protect the case from the burning propellant. [4-5]

\section{JUSTIFICATION OF THE WORK}

Characterization of reinforced rubbers for use as rocket motor insulators is presented, One such insulation is aramid fiber (Kevlar) in the pulp form (KP) [6] filled Ethylene Propylene Diene Monomer (EPDM) in the liquid form which is peroxide cured (PCA) and contains ammonium polyphosphate flame retardant agent (AP). Different formulations of Kevlar pulp with EPDM polymer were prepared to investigate the physical, mechanical and thermal properties. The difference in the formulations is the Kevlar pulp phr content (10-30 phr). The formulations were mixed using C.B. Bra bender mixer equipped with two sigma blades to attain uniform 
dispersion of the Kevlar pulp. The formulations were cured under a press ( $T=170$ ${ }^{\circ} \mathrm{C}, \mathrm{P}=28$ tons). Sheets with dimensions $(300 \times 150 \times 3 \mathrm{~mm}, 300 \times 150 \times 1 \mathrm{~mm})$ were made for investigation of the physical, mechanical, thermal and ablative properties.

\section{PHYSICAL AND MECHANICAL PROPERTIES}

According to ASTM the physical and mechanical properties were measured. A list of physical and mechanical properties is shown in Table (1) and Figures (1), (2).

\section{THERMAL PROPERTIES}

The determination of the thermal diffusivities of the cured thermal insulation compositions was done by the Nanoflash technique. [7] Using this method, the front side of a plane - parallel sample with a well defined thickness is heated by a short light or laser pulse. The resulting temperature rise on the back surface is measured versus time using an infrared detector. Analyzing the measured detector signal with appropriate mathematical models yields information on various thermophysical properties of the material. This satisfies the requirements for measurements of thermal diffusivities according to ASTM E 1461. Fig 3 shows the main components of the nanoflash instrument.

The determination of the specific heat capacities was done by doing differential scanning calorimetry (DSC). [8] The DSC Heat Capacity analysis calculates the actual specific heat capacity at any temperature in the DSC scan. The measurement is made by heating a test specimen at a fixed rate over a designated temperature range, where the specimen is held in thermal equilibrium before and after dynamic heating. The heat flow obtained from the specimen is recorded as a function of the actual sample temperature. This heat flow, normalized to the specimen mass and heating rate, is directly proportional to the specimen's specific heat capacity. To obtain specific heat capacity analysis we need three DSC graphs: a sample, a baseline, and a reference. The baseline data is used for baseline subtraction from the reference and sample data. Typically sapphire is used as the reference material.

With using sapphire calibrant as a reference and do DSC for base line (without sample). DSC of the material samples was done using samples around $8 \mathrm{mg}$. We obtained the resultant curves which relate the heat flow for every material composition with temperature for base line, sapphire calibrant, 10, $30 \mathrm{phr} \mathrm{KP}$, compositions. These are shown in Fig 4, 5, 6, 7 respectively where only DSC curves for $10,30 \mathrm{KP}$ content compositions were selected for representation.

To calculate the thermal conductivity $\mathrm{K}$ of the cured thermal insulation compositions, the formula $\mathrm{K}=\rho . \mathrm{A} . \mathrm{C}_{\mathrm{p}}$ is used where $\rho$ is the density of the material, $\mathrm{A}$ is the thermal diffusivity of the material and $C_{p}$ is the specific heat capacity of the material. A list of thermal properties is shown in Table (2) and Fig. (8), (9). 


\section{THERMAL DEGRADATION}

Another important aspect of the characterization of the material compositions includes defining the primary reactions in the decomposition of the material. [9] TGA (Thermo gravimetric) analysis is a very useful tool in establishing the primary reactions that occur. The data are useful in obtaining decomposition temperatures of the whole material composition. TGA of the insulation samples was done using samples of around $12 \mathrm{mg}$ in a temperature range from $25^{\circ} \mathrm{C}$ to $1000{ }^{\circ} \mathrm{C}$ with a heating rate $40{ }^{\circ} \mathrm{C} / \mathrm{min}$. The resultant curves which relate the weight $\%$ for every insulation composition with temperature for 10, $30 \mathrm{phr}$ KP compositions are shown in Fig. 10, 11 respectively where only TGA curves for 10, $30 \mathrm{KP}$ content compositions were selected for representation.

The TGA tests indicate for all compositions that an initial decomposition temperature for EPDM (matrix) occurs around $420{ }^{\circ} \mathrm{C}$ and the final decomposition is at $547{ }^{\circ} \mathrm{C}$ where EPDM decomposes to carbonaceous residue of free carbon. These provide a net effect of strong carbon based char which is highly erosion resistant. Also the tests indicate that an initial decomposition temperature for ammonium polyphosphate (flame retardant agent) occurs around $548{ }^{\circ} \mathrm{C}$ and the final decomposition is at 692 ${ }^{\circ} \mathrm{C}$. In addition TGA for the individual constituents (KP, AP and EPDM) was done alone. The TGA curve for KP alone is shown in Fig. 12.

The only stable ingredient above $1000{ }^{\circ} \mathrm{C}$ is Kevlar pulp which is stable up to 1450 ${ }^{\circ} \mathrm{C}$, in addition to the carbon based char remains from decomposition of EPDM. Not all $100 \%$ of Kevlar pulp will be stable up to $1450{ }^{\circ} \mathrm{C}$ but up to $80 \%$ of it decomposes which represents all the atoms inside the structure of Kevlar except carbon atoms. These $20 \%$ represent carbon based char which is highly erosion resistant.

As a conclusion from TGA curves the only stable material above $1000{ }^{\circ} \mathrm{C}$ will be the carbon based char remains from decomposition of EPDM and KP. So as Kevlar pulp phr increases in the insulation composition, the insulation efficiency increases with respect to decomposition.

\section{ABLATION TEST}

Another important aspect of the characterization of the material compositions includes measurement of ablation rate according to ASTM-E-285-80. [10] The ablation test was done by preparing a sample of the insulation material (30 phr KP) with $3 \mathrm{~mm}$ thickness, length $20 \mathrm{~cm}$ and width $20 \mathrm{~cm}$ and subjected to a high temperature torch. The sample characteristics before and after the test are shown in Table 3.

The resultant ablation rate is outstanding for rocket motor insulation. This is due to the KP content which itself has very high ablation resistance and stability up to 1450 ${ }^{\circ} \mathrm{C}$. The temperature in the back of the ablation test sample $\left(79^{\circ} \mathrm{C}\right)$ indicates that the insulation which contains Kevlar pulp is outstanding thermal insulation material. 


\section{CONCLUSION}

Increasing the Kevlar pulp phr (part per hundred ratio) content inside EPDM will improve the performance of EPDM as a solid rocket motor insulation with respect to tensile strength, ablation resistance, thermal diffusivity and thermal conductivity. However this will not give high performance with respect to decomposition resistance.

\section{FUTURE WORK}

It is intended to use hybrid reinforcements for elastomers where we complement the insufficient decomposition resistance of KP filled elastomers by the high temperature stable material, chopped carbon fiber (CCF) which is stable up to $3200^{\circ} \mathrm{C}$. The characteristics of chopped carbon fiber and Kevlar pulp, using the hybrid (CCF, Kevlar pulp) may have improved performance in ablation resistance and decomposition temperatures due to using CCF and thermal properties due to using Kevlar pulp. 
Table (1): Physical and mechanical testing results for different phr contents of KP

\begin{tabular}{|l|c|c|c|c|}
\hline Property & $\begin{array}{c}\text { Tensile } \\
\text { Strength } \\
\text { (MPa) }\end{array}$ & $\begin{array}{c}\text { Elongation } \\
\text { (\%) }\end{array}$ & $\begin{array}{c}\text { Density } \\
\left(\mathbf{g} / \mathbf{c m}^{\mathbf{3}}\right)\end{array}$ & $\begin{array}{c}\text { Hardness } \\
\text { (shore A) }\end{array}$ \\
\hline $\begin{array}{l}\text { EPDM + 10 phr KP + 60 phr AP + } \\
5 \text { phr PCA }\end{array}$ & 5.13 & 31.4 & 1.156 & 87.8 \\
\hline $\begin{array}{l}\text { EPDM + 15 phr KP + 60 phr AP + } \\
5 \text { phr PCA }\end{array}$ & 6.08 & 26.9 & 1.163 & 89.9 \\
\hline $\begin{array}{l}\text { EPDM + 20 phr KP + 60 phr AP + } \\
5 \text { phr PCA }\end{array}$ & 7.19 & 21.3 & 1.171 & 91.1 \\
\hline $\begin{array}{l}\text { EPDM + 25 phr KP + 60 phr AP + } \\
5 \text { phr PCA }\end{array}$ & 8.24 & 15.6 & 1.179 & 92.3 \\
\hline $\begin{array}{l}\text { EPDM + 30 phr KP + 60 phr AP + } \\
5 \text { phr PCA }\end{array}$ & 9.35 & 11.7 & 1.185 & 93.4 \\
\hline
\end{tabular}

Table (2): Thermal testing results for different phr contents of KP

\begin{tabular}{|l|c|c|c|}
\hline Property & $\begin{array}{c}\text { Thermal } \\
\text { diffusivity } \\
\left.\text { ( } \mathbf{m m}^{2} / \mathbf{s}\right)\end{array}$ & $\begin{array}{c}\text { Specific } \\
\text { heat } \\
\text { capacity } \\
\text { (J/kg.C) }\end{array}$ & $\begin{array}{c}\text { Thermal } \\
\text { conductivity } \\
\text { (W/m.C) }\end{array}$ \\
\hline EPDM + 10 phr KP + 60 phr AP + 5 phr PCA & 0.111 & 1834 & 0.235 \\
\hline EPDM + 15 phr KP + 60 phr AP + 5 phr PCA & 0.103 & 1801 & 0.216 \\
\hline EPDM + 20 phr KP + 60 phr AP + 5 phr PCA & 0.096 & 1778 & 0.2 \\
\hline EPDM + 25 phr KP + 60 phr AP + 5 phr PCA & 0.088 & 1756 & 0.182 \\
\hline EPDM + 30 phr KP + 60 phr AP + 5 phr PCA & 0.081 & 1741 & 0.167 \\
\hline
\end{tabular}

Table 3: Ablation rate test results

\begin{tabular}{|l|c|c|}
\hline \multicolumn{1}{|c|}{ property } & before & after \\
\hline Thickness of the sample $(\mathrm{mm})$ & 3 & 2.62 \\
\hline weight of the sample $(\mathrm{gm})$ & 36 & 34.2 \\
\hline Time (seconds) & \multicolumn{2}{|c|}{60} \\
\hline Temperature in front of sample $\left({ }^{\circ} \mathrm{C}\right)$ & \multicolumn{2}{|c|}{2010} \\
\hline Temperature in back of sample $\left({ }^{\circ} \mathrm{C}\right)$ & \multicolumn{2}{|c|}{0.01} \\
\hline Resultant ablation rate $(\mathrm{mm} / \mathrm{sec})$. & \multicolumn{2}{|c|}{$0.09-0.2$} \\
\hline Regular ablation rate $(\mathrm{mm} / \mathrm{sec})$. & \multicolumn{2}{|c|}{} \\
\hline
\end{tabular}




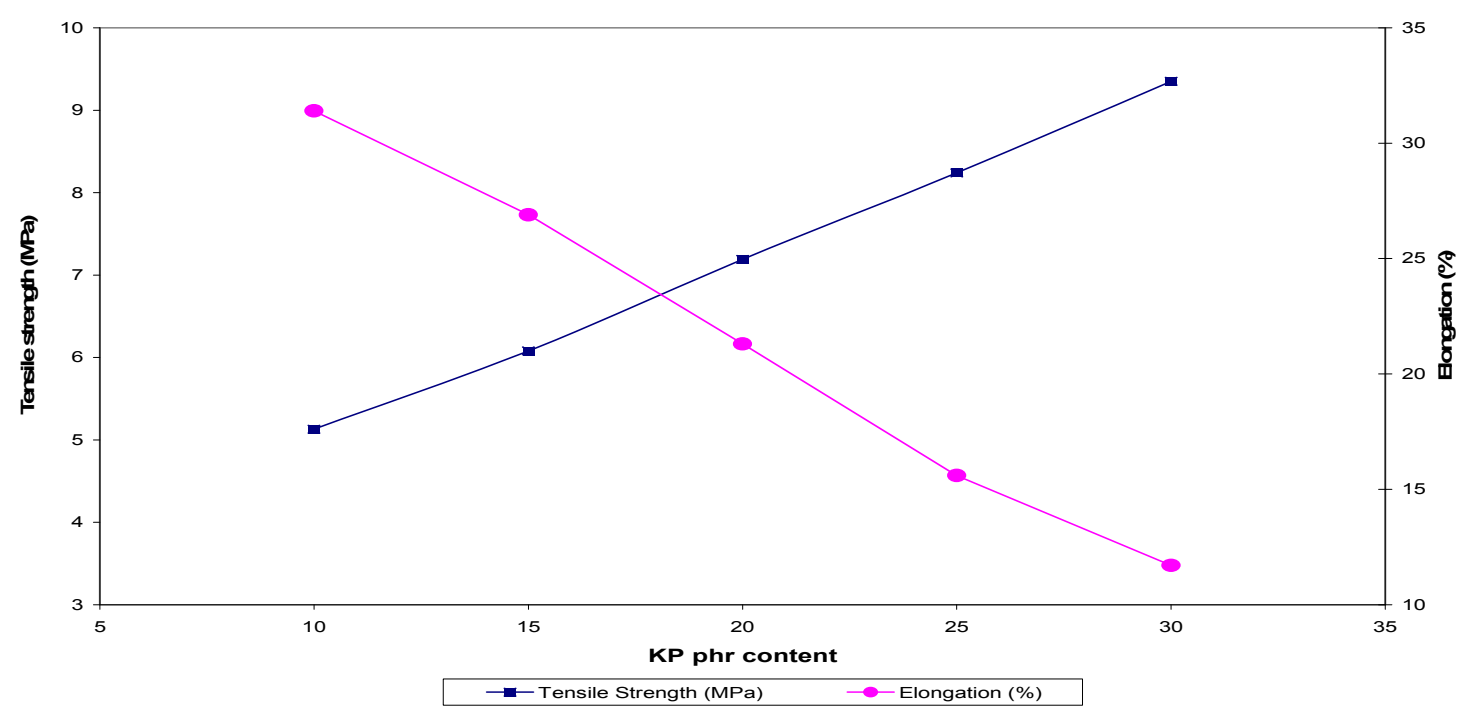

Fig (1): Tensile strength \& Elongation of the material as a function of KP phr content

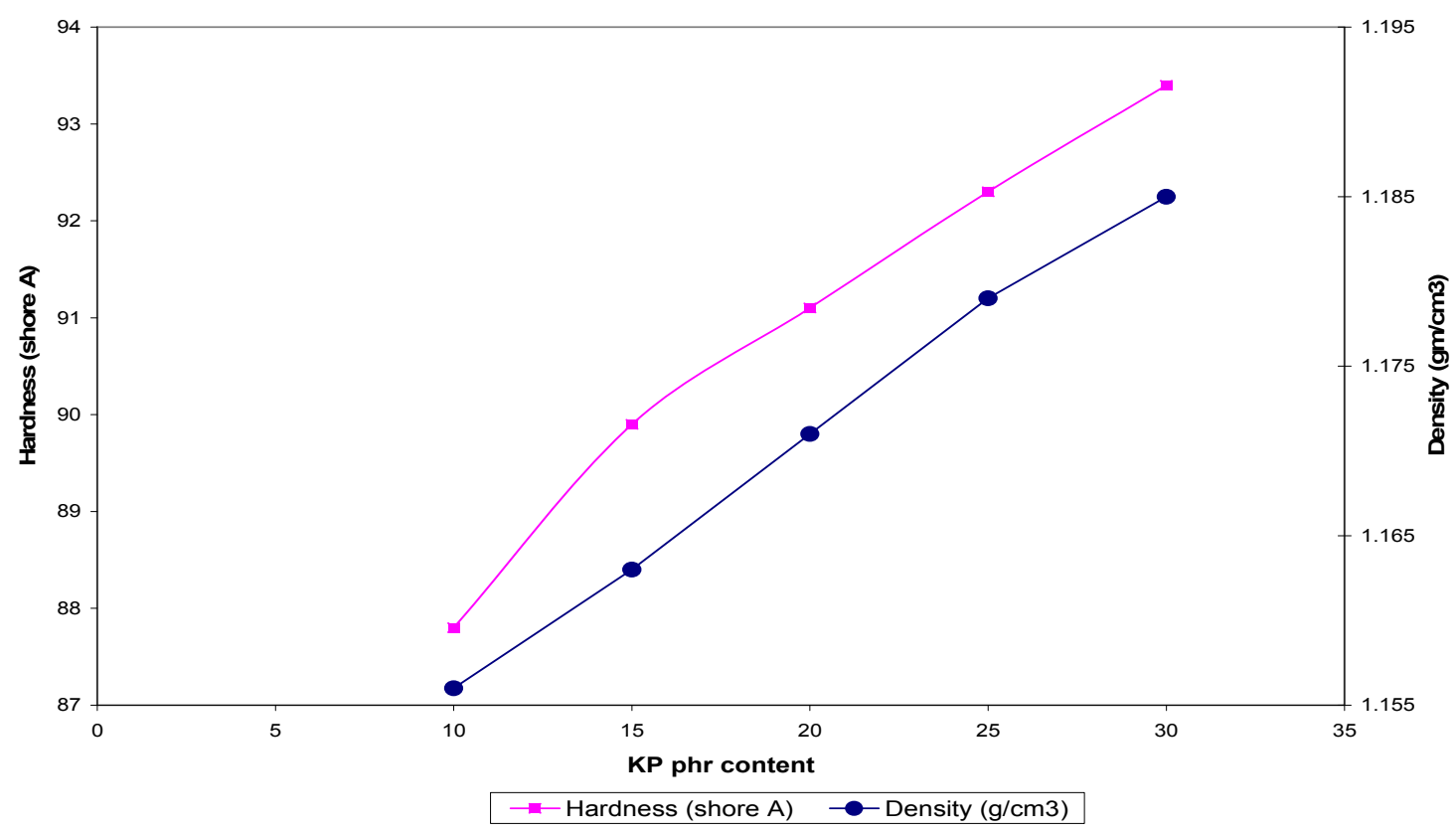

Fig (2): Hardness \& Density of the material as a function of KP phr content 


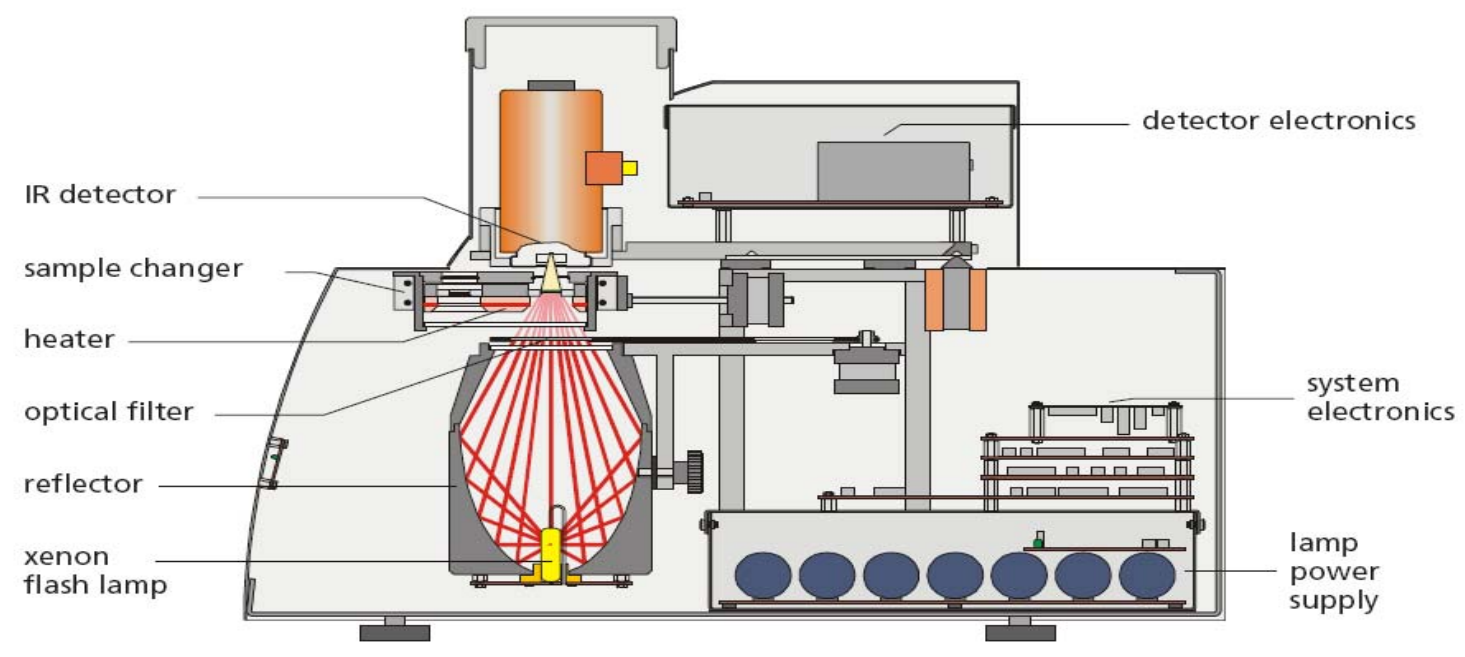

Fig (3): The nanoflash instrument main measurement components

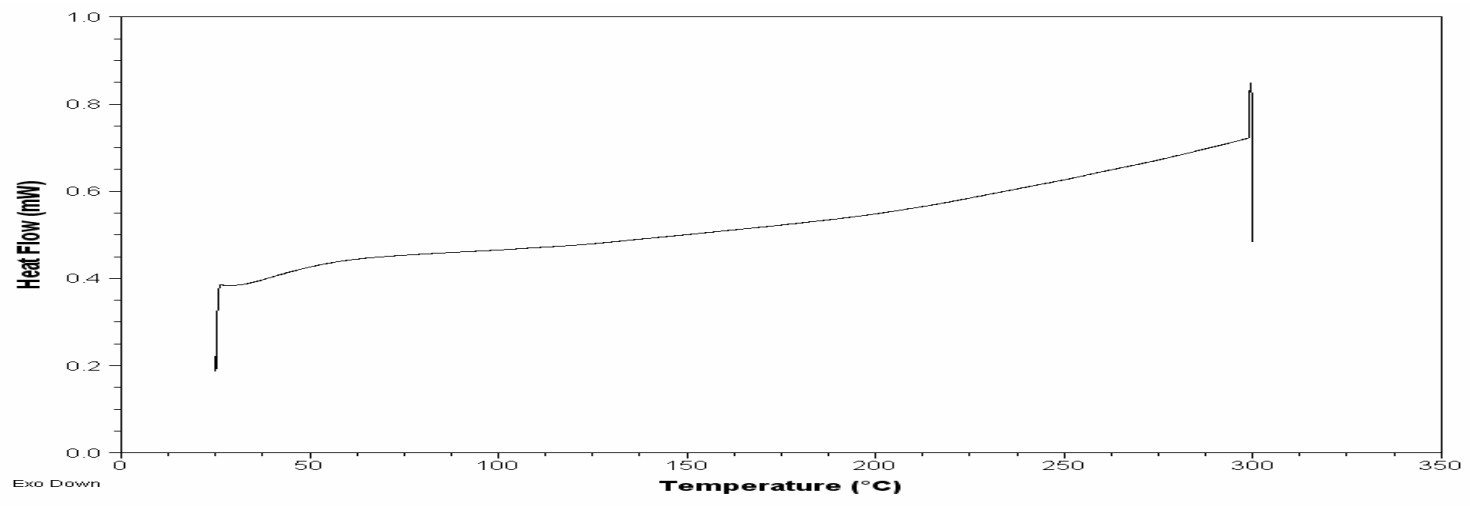

Fig (4): DSC curve for base line (without sample)

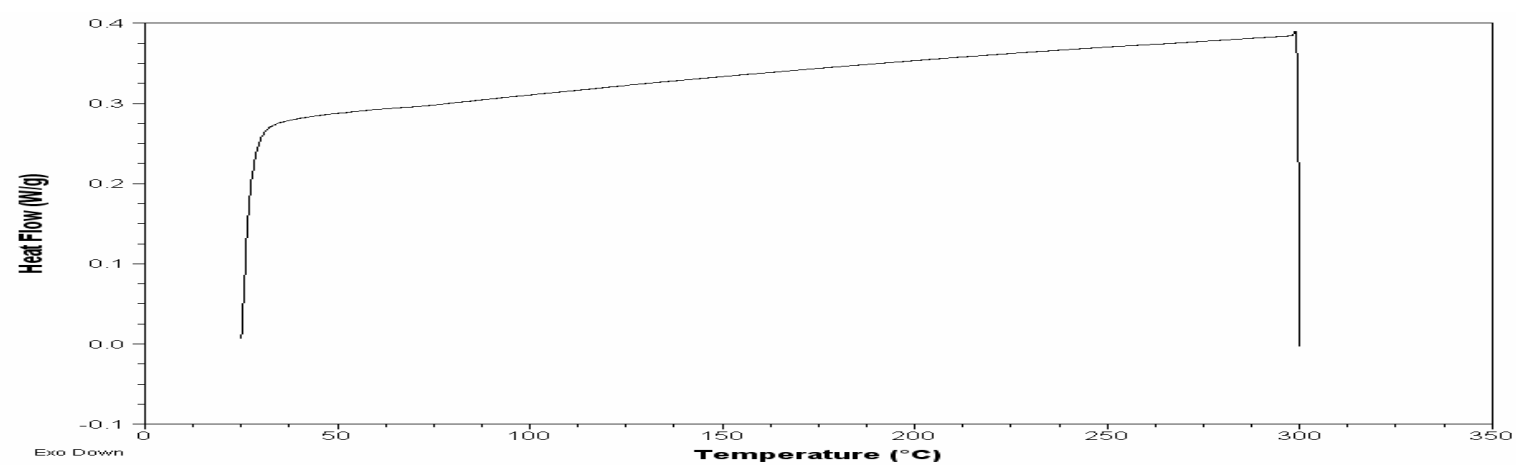

Fig (5): DSC curve for sapphire calibrant 


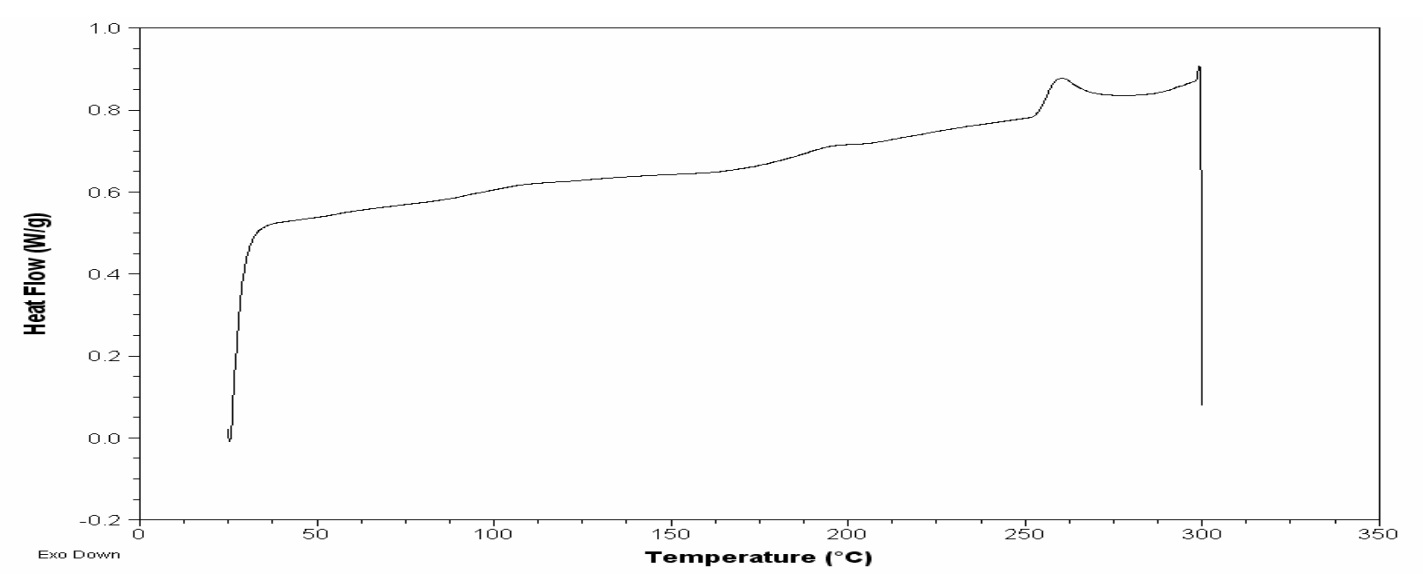

Fig (6): DSC curve for insulation composition having $10 \mathrm{phr}$ KP content

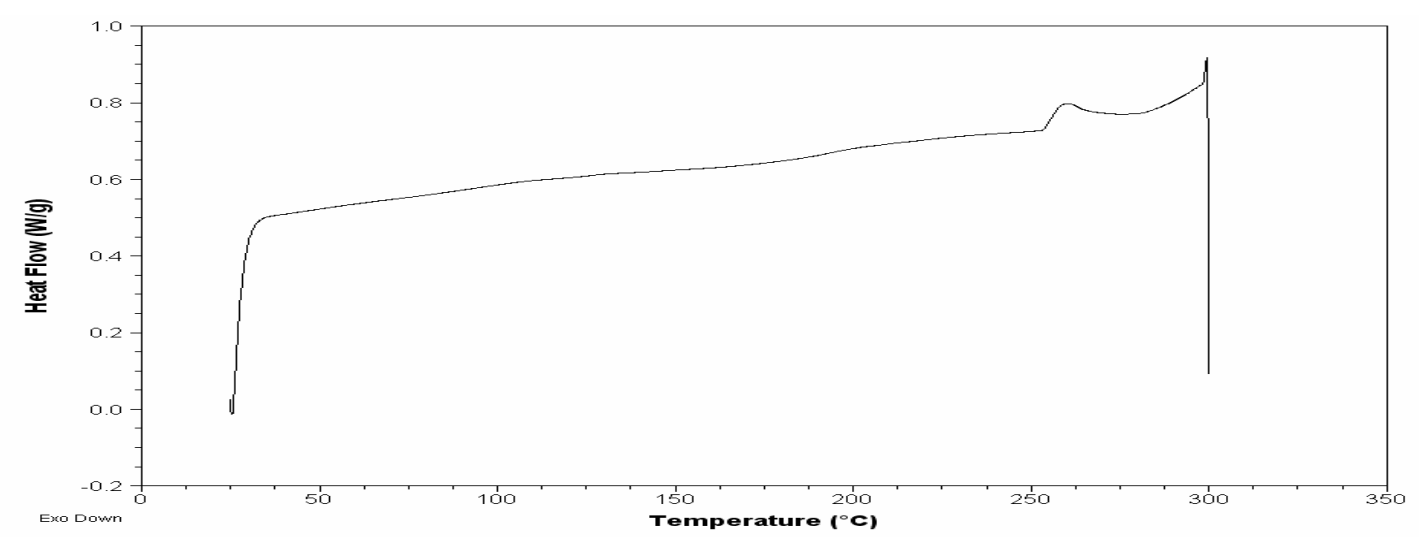

Fig (7): DSC curve for insulation composition having $30 \mathrm{phr}$ KP content

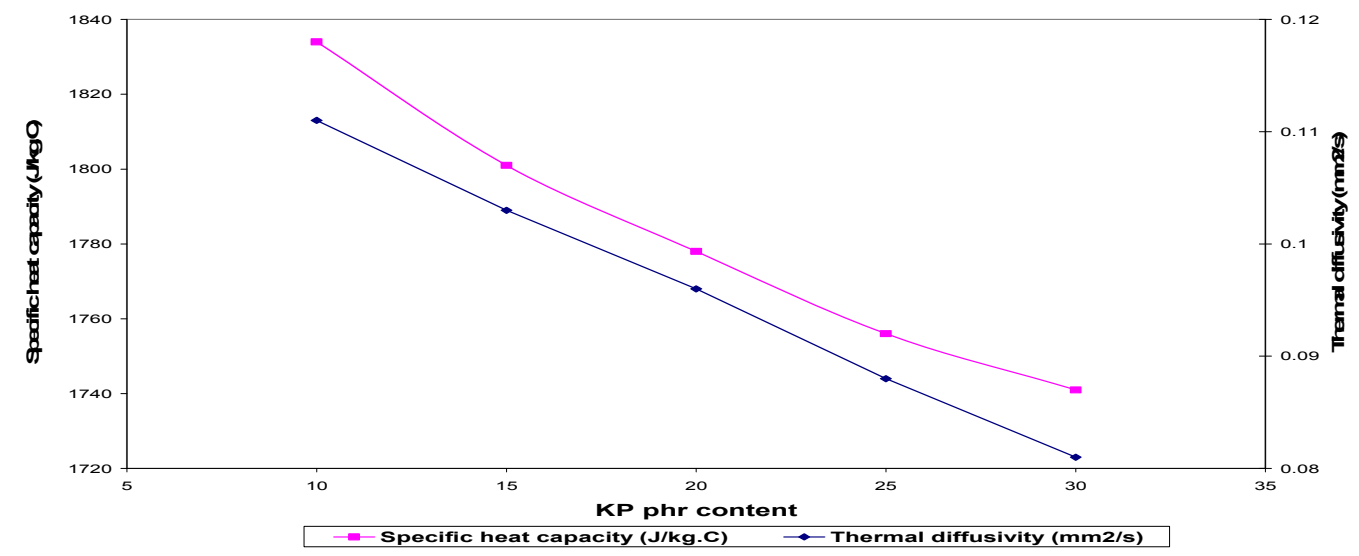

Fig (8): Specific heat capacity \& thermal diffusivity of the material as a function of KP phr content 


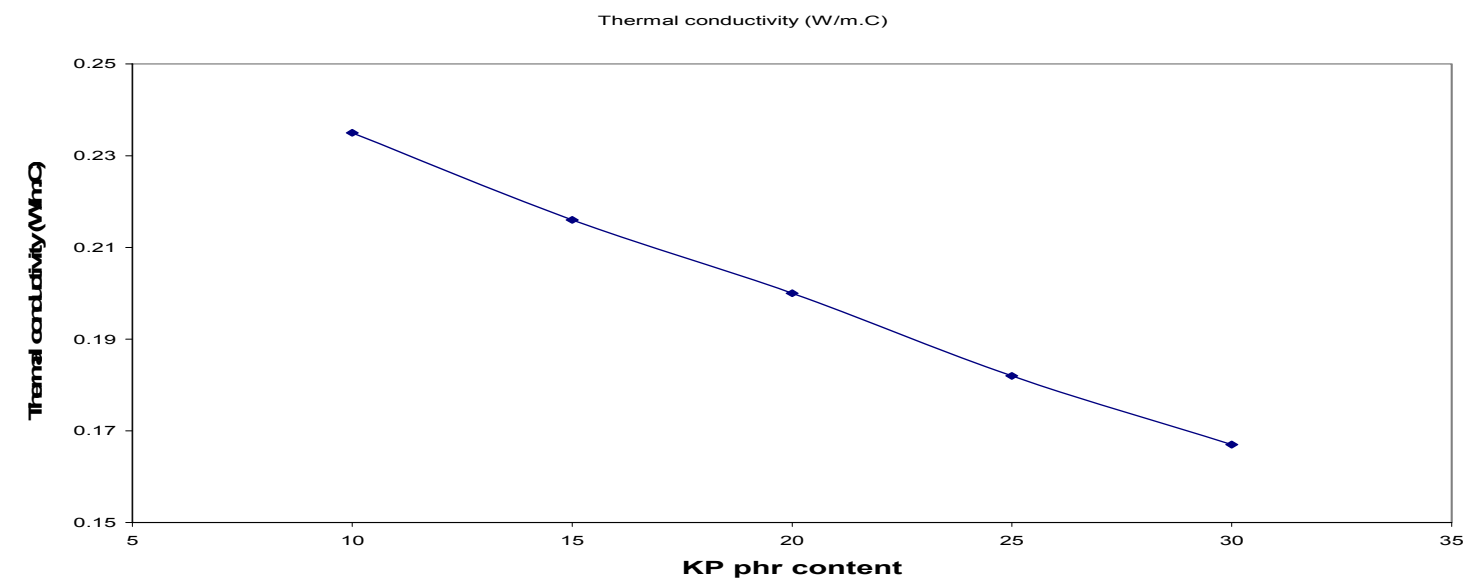

Fig (9): Thermal conductivity of the material as a function of $\mathrm{kp}$ phr content

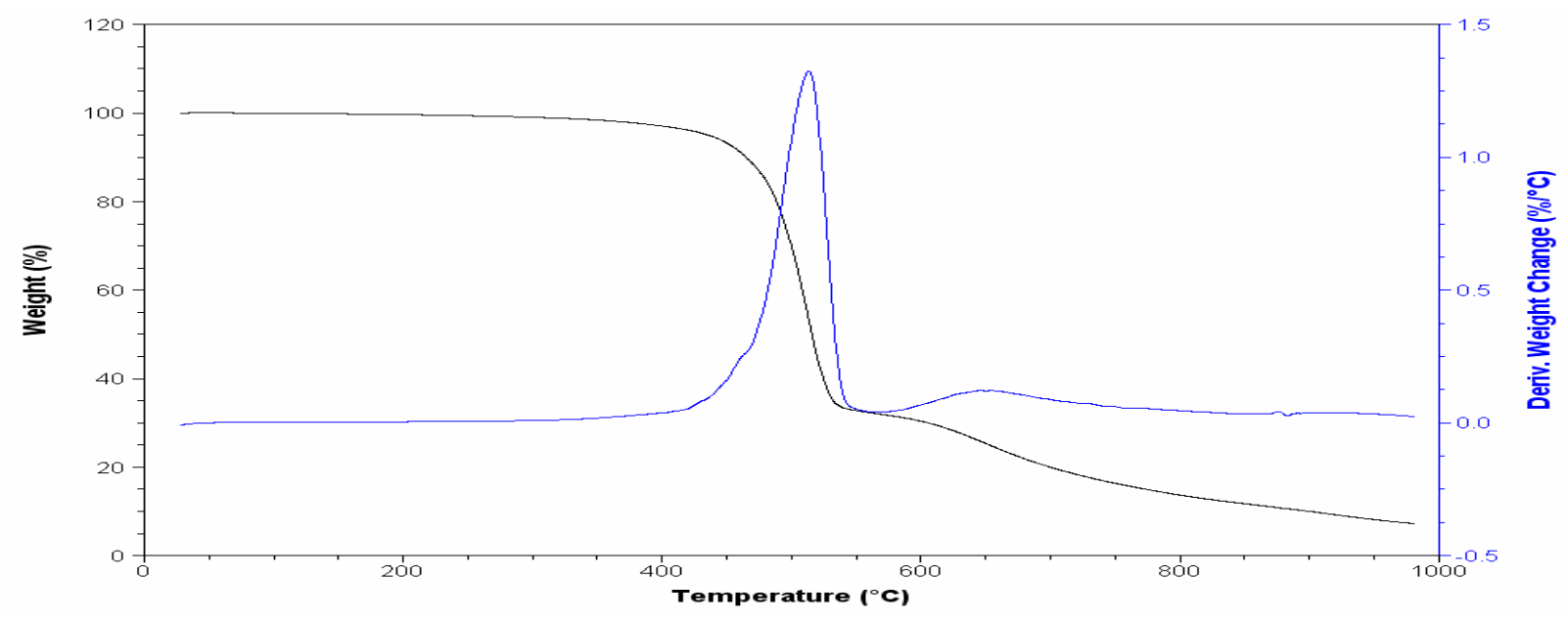

Fig (10): TGA curve for insulation composition having $10 \mathrm{phr}$ KP content

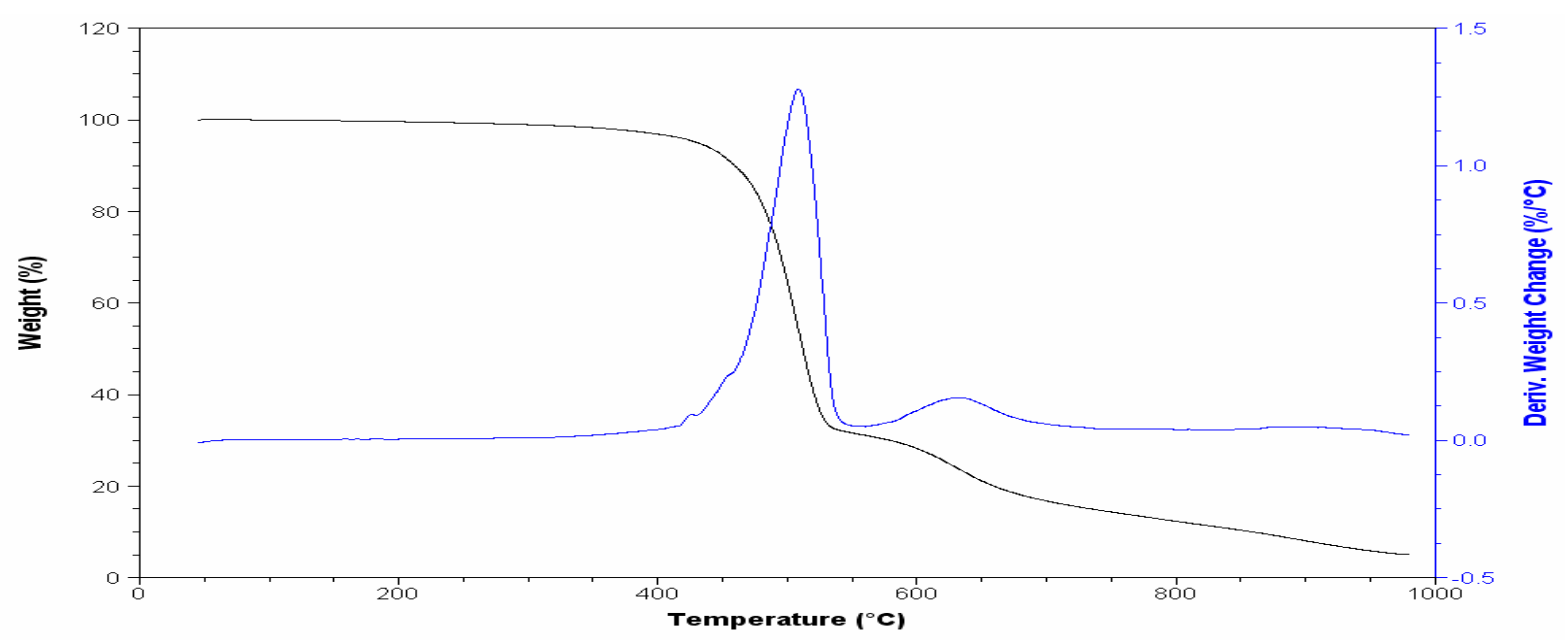

Fig (11): TGA curve for insulation composition having $30 \mathrm{phr}$ KP content 


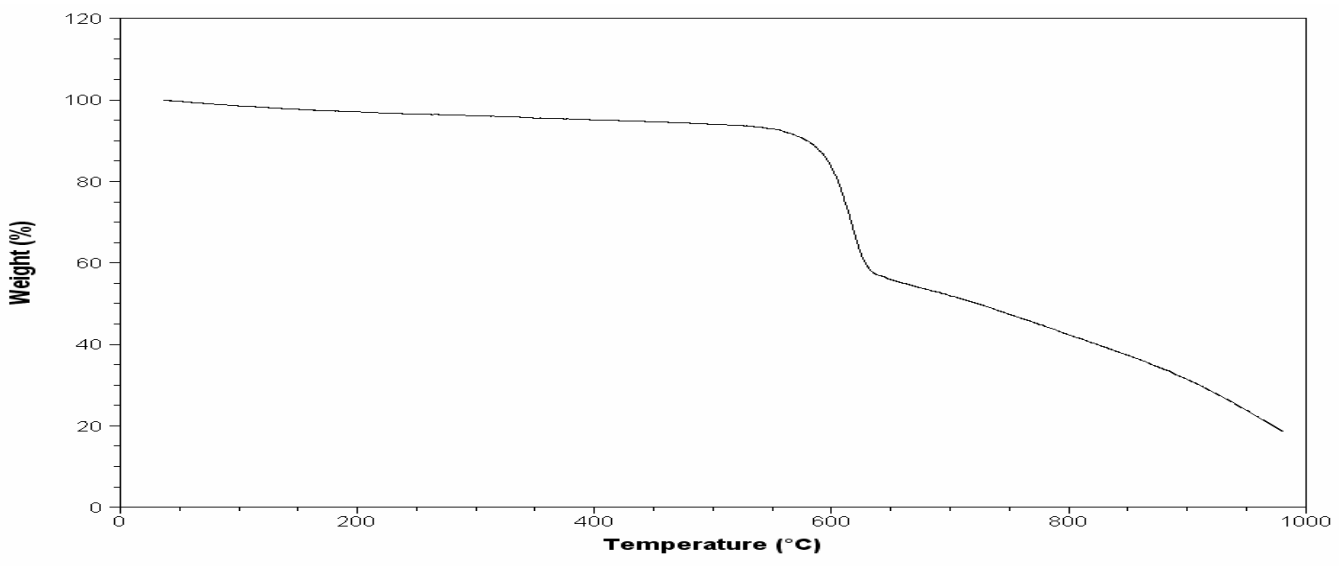

Fig (12): TGA curve for KP alone 


\section{ACKNOWLEDGEMENT}

I would like to express my gratitude to the Egyptian armed forces for giving me the possibility to complete this thesis. I want to thank the department of mechanical and industrial engineering, Concordia University, Montreal, Canada for helping me to do this work.

\section{REFRENCES}

[1] C.M. Bhuvaneswari, M.S. Sureshkumer, S.D. Kakade, and Monaj Gupta. "Ethylene - propylene rubber as a futuristic elastomer for insulation of solid rocket motor". Defence science journal, Vol 56, No.3 july 2006 pp.309-320.

[2] Guillot, David. G. Novel, US Patent no 6787586, Sept. 7, 2004 'EPDM rocket motor insulation.

[3] Roberto Isopi, Eros Pittarelli, Antonio Sebasta. "Development of low density insulators for space motors". SNIA Viscosa, Space and defence Division Via Sicilia 162, rome, Italy, 1979.

[4] R. E. Morgan, A. S. Prince, and S. A. Selvidge, and J. Phelps, C. L. Martin,T. W. $L$ awrence. "Non - asbestos insulation testing using a plasma torch". july 2000.

[5] Wang Zheng, Yongqiang $\mathrm{Hu}$, Solid Rocket Motor, $1^{\text {st }}$ ed., Astronautics industry Press, Beijing, 1993, pp. 229-236.

[6] Dupont advanced fibers systems, Technical guide for KEVLAR, USA, 2005.

[7] Guillot, David. G. Novel, US Patent no 6893597, May 17, 2005 'Method of insulating a case of a solid propellant rocket motor".

[8] Guillot, David. G. Novel, US Patent no 5498649, March 12, 1996 'Low density thermoplastic elastomeric insulation for rocket motors'.

[9] Guillot, David. G. Novel, US Patent no 5399599, March 21, 1995 'Thermoplastic elastomeric internal insulation for rocket motors for low temperature applications.

[10] A. J. Kinloch and R. J. Young, Behavior of polymers, Elsevier Science Publishers, Ltd., London, 1983. 